\title{
Prochelator tupuhi sp. nov., the first record of Desmosomatidae Sars, 1897 (Crustacea: Isopoda) from New Zealand waters*
}

\author{
SASKIA BRIX ${ }^{1} \&$ NIEL L. BRUCE ${ }^{2}$ \\ ${ }^{1}$ German Centre for Marine Biodiversity Research (DZMB), Senckenberg Research Institute, Biocentrum Grindel, Martin-Luther-King \\ Platz 3, 20146 Hamburg, Germany; sbrix@ senckenberg.de \\ ${ }^{2}$ National Institute of Water and Atmospheric Research Ltd., Private Bag 14901, Kilbirnie, Wellington, New Zealand; \\ Current address: Museum of Tropical Queensland, 70-102 Flinders Street, Townsville, 4810 Australia; niel.bruce@qm.qld.gov.au
}

*In: Martínez Arbizu, P. \& Brix, S. (Eds) (2008) Bringing Light into Deep-sea Biodiversity. Zootaxa, 1866, 1-574.

\begin{abstract}
Prochelator tupuhi sp. nov. is the first record of the genus Prochelator Hessler, 1970 from Southern Hemisphere waters, and the first record of the family Desmosomatidae from New Zealand. The new species can be distinguished from all other species of the genus by the following characters: body elongate, without spine-like ventral elongations on pereonites $1-4$, pereonite 1 as high as pereonite 5, mesial lobe of the maxilla much shorter than in the other species of the genus, reaching only half the length of the lateral lobe, carpus of pereopod 1 distinctly produced at the base of the claw, propodus broadest at the articulation to the carpus, tapering distally.
\end{abstract}

Key words: Isopoda, Desmosomatidae, Prochelator, New Zealand, taxonomy, new species

\section{Introduction}

The asellote family Desmosomatidae Sars, 1897 has a global distribution. Most species of the genus Prochelator Hessler, 1970 have been described from the North Atlantic Ocean (Brenke et al. 2005). Examination of the NIWA collections reveal at least a further ten species in six genera, namely Mirabilicoxa Hessler, 1970, Chelator Hessler, 1970 (3 species), Desmosoma Sars, 1864, cf. Eugerda Meinert, 1890 (2 species), Eugerdella Kussakin, 1965 (2 species) and Prochelator Hessler, 1970. This investigation indicates that the approximate expected diversity for Desmosomatidae in New Zealand waters will be similar to that which is known for other regions. The NIWA collections are extensive and the largest marine invertebrate collection in New Zealand, but prior to 2007, an epibenthic sledge (EBS) was not used for sampling around New Zealand (the sole exception being by Lincoln in October/November 1979 and April 1980 (see Lincoln 1985). The Brenke design of the EBS (Brenke 2005) was first deployed on two back-to-back expeditions under the Oceans 2020 program. Given that the present study describes the first record of Desmosomatidae from New Zealand waters, and that collecting efforts for "small macrofauna" has in the past been minimal, it would be reasonable to expect "comparable" diversity within the family to that of other regions with further EBS sampling.

Recent collections made in the Atlantic sector of the Southern Ocean (ANDEEP material, ANtarctic benthic DEEP-sea biodiversity, colonisation history and recent community patterns); personal observation and see Brandt et al. 2004, data for Brandt et al. (2007a, b) include a further 11 undescribed species of Prochelator. Samples from southern Australian waters (Poore et al. 1994, Brix 2006) contained no specimens of the genus Prochelator. The NIWA collection contained two species of Prochelator and this paper describes one these species, the first record of Desmosomatidae from New Zealand waters. 
Prochelator is known from the Arctic Ocean (Kussakin 1999), the Nordic Seas (Brandt 1993, Svavarsson 1993), around Iceland (Brix \& Svavarsson, unpublished data), the western North Atlantic Ocean (Hessler 1970), the South Atlantic Ocean (Brandt et al. 2005, Brenke et al. 2005) and the Atlantic sector of the Southern Ocean (ANDEEP I- III), while desmosomatids were highly diverse in all samples from the Weddell Sea and around the Scotia Arc (Brandt et al. 2007a, b).

\section{Methods}

Specimens were identified using a Leica MZ 9.5 dissecting microscope and illustrated using a "Leitz MI 85" compound microscope (ZMH, Hamburg) and an Olympus BX 20 with a camera lucida. The methods are described in Brix (2006). The terminology of the most important setal types is presented in Brix (2007) or follows Watling (1989).

The following collection material was studied for comparison:

USNM 125107

USNM 125108

USNM 125109

USNM 138731

AM P59082

AM P59075

AM P59197

AM P58781

ZMUC CRU
Prochelator abyssalis Hessler, 1970, holotype female

Prochelator hampsoni Hessler, 1970, holotype female

Prochelator incomitatus Hessler, 1970, holotype female

Prochelator sarsi (George, 2001), holotype female

Prochelator litus Hessler, 1970, paratype female

Prochelator abyssalis Hessler, 1970, paratype female

Prochelator hampsoni Hessler, 1970, paratype female

Prochelator lateralis (Sars, 1897), other material

Prochelator serratum, nontype Isopoda, det. E. Fresi, Ischia N., Italy 80-110 m, May 1968

Prochelator lateralis (Sars, 1897), syntypes

ZMH K-40331 A-K Prochelator angolensis Brenke, Brix und Knuschke, 2005, holotype female

ZMH K-40322 to K-40323Prochelator angolensis Brenke, Brix und Knuschke, 2005, paratypes female

Abbreviations: $\mathrm{P} 1-7=$ pereopods 1-7; Plt $=$ pleotelson; $\mathrm{Pl} 1-5=$ pleopods $1-5 ;$ Prn 1-7 = pereonites 1-7; $\mathrm{ZMH}=$ Zoological Museum of Hamburg; ZMUC = Zoologisk Museum, University of Copenhagen; AM = Australian Museum, Sydney; NIWA = National Institute of Water and Atmospheric Research, New Zealand; USNM = United States National Museum of Natural History, Smithsonian Institution, Washington DC.

\section{Taxonomy}

Desmosomatidae Sars, 1897

Eugerdellatinae Hessler, 1970

\section{Prochelator Hessler, 1970}

Synonymy: Prochelator Hessler, 1970: 27-28; Mezhov, 1986: 139; Kussakin, 1999: 278; George, 2001: 1840; Brenke, Brix and Knuschke, 2005: 180.

Type species: Eugerda lateralis Sars, 1899; original designation Hessler (1970).

Composition: P. angolensis Brenke, Brix \& Knuschke, 2005; P. abyssalis Hessler, 1970; P. hampsoni Hessler, 1970; P. incomitatus Hessler, 1970; P. lateralis (Sars, 1899); P. litus Hessler, 1970; P. sarsi George, 2001; P. uncatus Hessler, 1970; P. kussakini Mezhov, 1986; P. serratum (Fresi \& Schiecke, 1969); P. tupuhi sp. nov. 
Diagnosis: Pereopod 1 large, carpo-chelate, dactylus and propodus forming movable counterpart to large spine-like claw-seta on distal end of carpus. Inferior margin of carpus of pereopod 1 with one midventral seta and a slender seta distally proximal to claw-seta. Pleotelson with posterolateral spines.

Generic remarks: The genus Prochelator was erected by Hessler (1970) who transferred the type species from Eugerdella to Prochelator and described five new species of Prochelator. Desmosoma serratum was recently transferred to Prochelator by Brenke et al. (2005). Five publications have subsequently defined the genus (Hessler 1970, Mezhov 1986, Kussakin 1999, George 2001 and Brenke et al. 2005). The present diagnosis differs from the diagnosis presented by George (2001) in including species with uniramous uropods. In Desmosomatidae, the uropods are biramous in the plesiomorphic condition but the exopod is reduced and is completely absent in approximately half of the described species. Thinking about Hessler's (1970) statement about reduction of the exopod, the loss of the exopod might be homoplasious within the family. Although the phylogenetic significance of these reductions is questioned due to the presence or absence in species of the same genus, the reduction may serve well as species-level diagnostic character, but not as a generic character. Precise definition of the apomorphies is important, as the genera Prochelator and Chelator closely resemble each other. According to Hessler (1970) the prefix "Pro-" refers to the fact, that Chelator is probably derived from a species of Prochelator. But accepting phylogenetic sytematics and the concept of monophyly, a present-day taxon cannot be assumed to be derived from another present-day taxon, but rather both are derived from a common ancestor.

To assess the taxonomic position of Prochelator and Chelator, a detailed discussion of all characters (possible apomorphies) and a phylogenetic analysis would be necessary. The principal character shared by Prochelator and Chelator is the chela of pereopod 1. Chelator can be distinguished from Prochelator by the ventral projection at the base of the claw-seta of the former. This projection is the only distinguishing character that can be identified when comparing generic diagnoses of both genera.

The ventral setae on the carpus of pereopod 1 were so uniform between the species that Hessler (1970) assigned to Prochelator, that he gave them the formal designation of "accessory setae". Hessler (1970) used this term for Prochelator but not for Chelator. He describes the ventral row of small setae on the lower margin of the carpus in species of Chelator as a row of setae, of which none can be labelled as "accessory seta". The term "accessory seta" is confusing and may be synonymised with the term "major seta" (Hessler 1970). Both terms are not used in the present paper; instead the setal types on the articles of the pereopods are described. A single midventral seta on the lower margin of the carpus is unique to Prochelator. This midventral seta can be used to distinguish Prochelator and Chelator, in addition to the projection at the base of the claw-seta listed as the only distinguishing character in the paragraph above.

Other desmosomatid species with a chelate pereopod 1 can be distinguished from Prochelator and Chelator by apomorphies. Species included in Oecidiobranchus possess a propodus that is more enlarged than the carpus with the dactylus folding against the ventral margin of the propodus. Unique to Oecidiobranchus is the small branchial chamber (Hessler 1970). Disparella possess a large cephalic spine at the point of insertion of the antennula. Such a cephalic spine is also found e.g. in Prochelator lateralis and P. uncatus, but not in any species of Chelator. The distinguishing apomorphy of Disparella, which separates the genus from Prochelator, is the elongate slender propodus (more than 3.5 times long as wide) and the setation on the ventral margin of the carpus of pereopod 1. Disparella possess a well defined row of setae behind the claw-seta. Such a row is not found in Prochelator or Chelator. Pereopods 2-4 of Disparella species are obviously setose (carpus > 20 setae, propodus $>8$ setae in adult) while in Prochelator the carpus of the anterior pereopods have no more than 10 setae in a row (except $P$. hampsoni).

Although the comparison of characters shows that Prochelator and Chelator are very similar, Prochelator and Chelator should be treated as separate genera based on the following reasoning: it is not possible to homologize the setae on the ventral margin of the carpus of pereopod 1, and no transformation series can be postulated explaining how the midventral setae (Prochelator) and the few small setae (Chelator) originated. 
The uniramous uropod in $P$. incomitatus and $P$. angolensis may have evolved convergently because the loss of the exopod is an apparently homoplasious character state as it occurs in genera that are otherwise widely disparate; the body form of females differs clearly between the two genera; posterolateral spines on the pleotelson are always present in females of Prochelator while in females of Chelator these posterolateral spines are absent. Furthermore, females of Chelator are more compact and the pereonites are rounded, while species of Prochelator have a different profile from lateral view. While in some species of Prochelator the posterior pereonites and the pleotelson are flattened, in species of Chelator the pleotelson is as high as pereonite 5, the rounded pleotelson form giving the body outline a more compact look than in Prochelator. In Chelator the first four body segments are more compact than in Prochelator (the first pereonite in Chelator twice as high as pereonite 5).

\section{Prochelator tupuhi sp. nov. (Figs. 1-5)}

Material examined:Holotype: $\&$ (preparatory, $3.1 \mathrm{~mm}$ ), east of Christchurch, South Island, western Chatham Rise, $44^{\circ} 30.10^{\prime} \mathrm{S}, 174^{\circ} 18.79$ 'E, 25 Oct 1979, 760 m, stn. S147 (NIWA 33747).

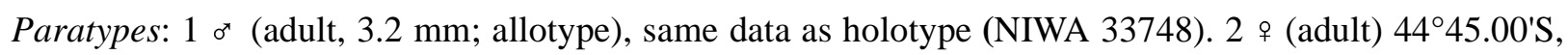
174³0.00'E, 18 Aug 1966, 765-854 m, stn F753 (NIWA 33749). 1 \% (adult) stn. F755 and 2 \% stn. S/ 47(NIWA 33750).

Type locality: Western Chatham Rise, east of Christchurch, South Island, New Zealand, $44^{\circ} 30.10^{\prime S}$, $174^{\circ} 18.79^{\prime} \mathrm{E}$.

Distribution: Eastern New Zealand; at depths of 760 to $864 \mathrm{~m}$, from the general type locality at more than one station.

Diagnosis: Body widest at pereonite 2; length about 4.6 times longer than width of pereonite 2. Pereonites $1-4$ in female slightly higher than pereonites $5-7$ in lateral view, in male as high as pereonites $5-7$. Pereonite 1 length 1.4 times pereonite 2 length. Pereonite 5 length 0.8 times width. Coxae $1-4$ anteriorly produced, each with robust acute setae. Pereopod 1 carpus broadest at articulation of propodus, slightly produced at base of claw-seta. Carpus of pereopods $2-4$ about twice as long as carpus of pereopod 1. Pleotelson with posterolateral spines located at 0.6 of pleotelson length. Uropods biramous, exopod about half as long as endopod.

Description of holotype (Fig. 1): Body $3.1 \mathrm{~mm}$ long, 4.68 times longer than width of Prn 2. Prn 1 width 1.42 times cephalon width in dorsal view. Prn 1 length 1.5 Prn 2 length, 0.84 Prn 2 width. Prn 5 width 0.82 length, anterior margin straight, lateral margin slightly convex. Coxae $1-4$ produced, with large acute robust setae. Pleotelson length 0.98 width, large posterolateral spines present. Lateral margins convex, posterior margin slightly rounded.

Antennula (Fig. 2) with six articles. Article 11.69 width, with four broom setae. Article 2 length 6.43 width, 2.01 article 1 length; distally with two large articulated broom setae and two small slender setae, marginally with two small slender setae. Article 3 length 3.5 width, with one short slender seta, article 4 length 3.3 width, distally with one broom seta, distal article length 3.5 width, terminally with one aesthetasc, one broom seta and two long slender setae. Articles 2 - 5 length relative to article 1: 2.01: 0.64: 0.5: 0.45: 0.32.

Antenna (Fig. 2) incomplete or partly missing, only four articles available.

Mandible (Fig. 2) palp article 1 with one small distal seta, article 2 ventrodistally with two small setulate setae, dorsally with rows of numerous fine microtrichia apical article with nine ventral seta, distal one longest. Incisor process with three teeth. Lacinia mobilis of left mandible with three teeth, spine row containing eight spines. Molar process with 13 fine setae.

Maxillula (Fig. 2) mesial lobe about 0.7 lateral lobe length, with 25 setae. Lateral lobe 3.75 times longer than wide, marginally with pairs of fine microtrichia terminally with 12 strong robust setae. 


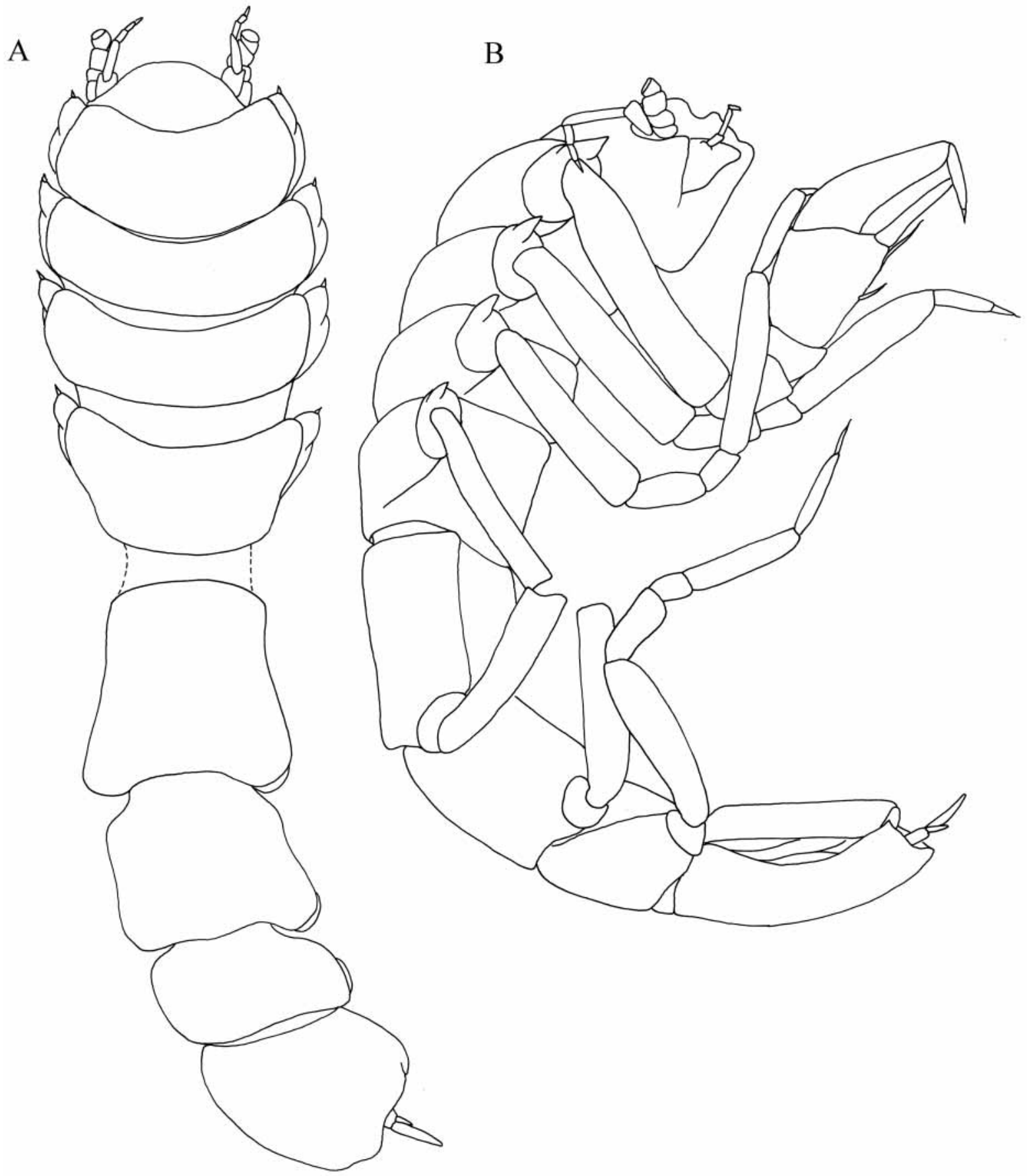

FIGURE 1: Prochelator tupuhi sp. nov., holotype female, habitus dorsal (A, pereonites 5-7 and pleotelson not precise in dorsal view, pleotelson contorted to the left side of specimen), lateral (B).

Maxilla (Fig. 2) mesial lobe 0.48 length of lateral lobes, terminally with 21 setae. Lateral lobe (one lobe lost during dissection) basally with two slender setae, terminally with 18 setae.

Maxilliped (Fig. 2) epipodite length 3.85 width, length 1.06 endite length. Endite with two retinaculae, terminally with numerous fine setae. Margin of endite and palp articles $1-3$ with row of fine setae. Palp article 2 with three setae on mesial margin and two setae on lateral margin, article 3 with five setae on mesial margin and one seta on lateral margin, article 4 with two setae, article 5 with three setae. Article 1 length 0.45 width, article 2 length 0.76 width, article 3 length 1.04 width, article 4 length 2.4 width, article 5 length 1.5 width. 


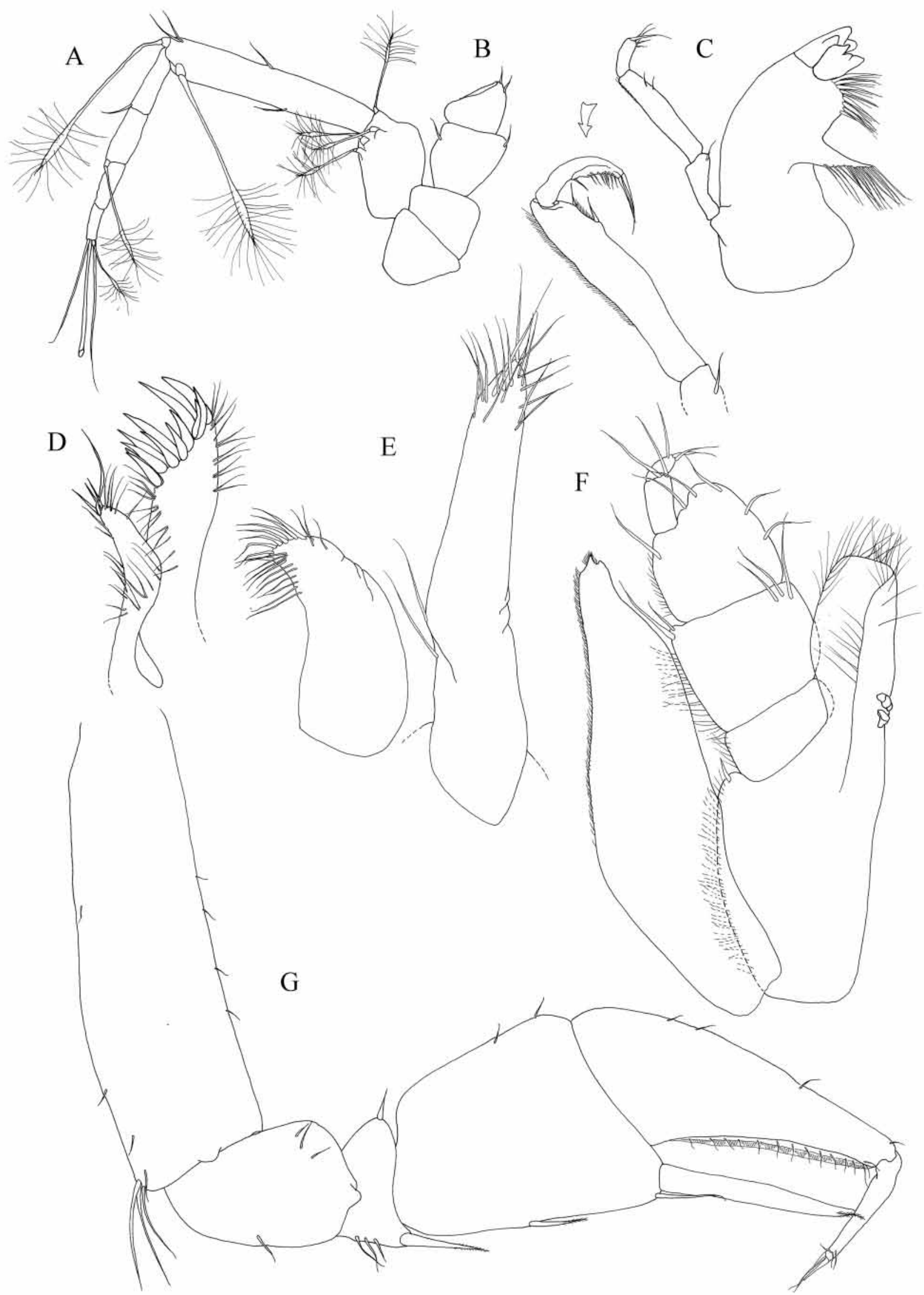

FIGURE 2: Prochelator tupuhi sp. nov., paratype female, antennula (A), antenna (B), mouthparts (C-F): left mandible (C), maxillula (D), maxilla (inner and outer lobe) (E), maxilliped (F), P 1 (G) 


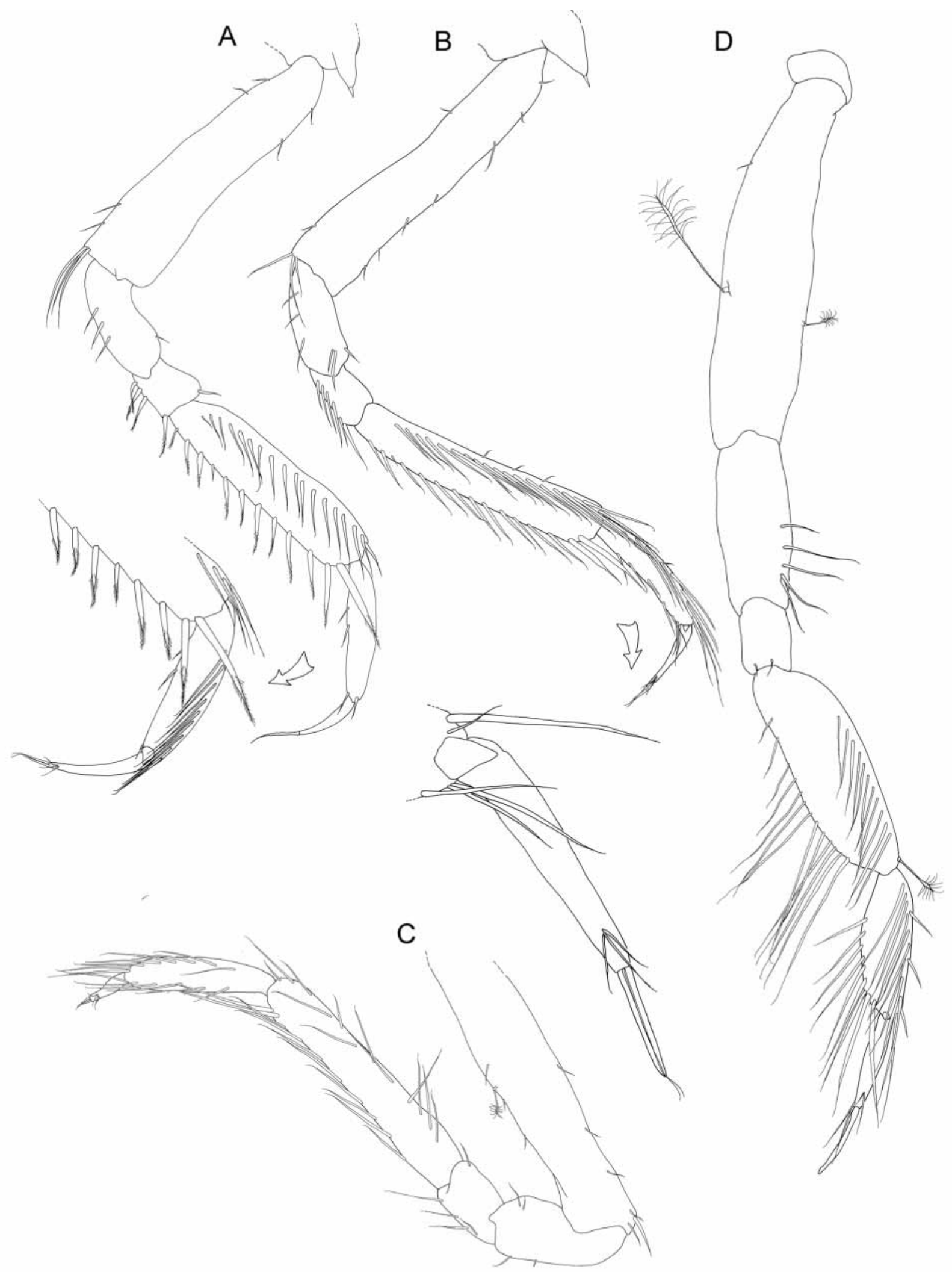

FIGURE 3: Prochelator tupuhi sp. nov., paratype female, pereopods (A-D): P 2 (A), P 3 (B), P 4 (C), P 5 (D).

Pereopod 1 (Fig. 2) Basis length 3.48 width, ventrally proximal to ischium with three slender setae, marginally with eight small setae. Ischium length 1.34 width, with few small setae. Merus length 0.32 width, ventrally with three small setae, ventrodistally with one robust distally setulate seta, dorsally one stout simple seta. Carpus length 1.42 width, distoventrally with large spine-like claw-seta and slender penultimate seta, 
medioventrally with one small distally setulate seta, dorsally two small setae. Propodus length 2.82 width, dorsally with four small setae, ventrally fringed with fine setae inserted in cuticular membrane and 14 small setae. Dactylus length 6 times width. Claw of dactylus with one cuspidate and one conate setae, two slender setae medially.

Pereopod 2 (Fig. 3) Basis length 4.4 width, ventrally proximal to ischium with three slender setae. Ischium length 2.3 width, ventrally with three simple setae, dorsally with one small seta. Merus length 4.31 width, ventrally with four distally setulate setae, distodorsally with one simple seta. Carpus length 5.12 width, with ventral and dorsal rows of setae, ventrally with 12 distally setulate setae, dorsally 18 simple setae. Propodus length 5.12 width, ventrally with three small setae, distodorsally one simple seta. Dactylus length 6 times width. Claw of dactylus with one conate seta.

Pereopod 3 and 4 are similar to pereopod 2, differing only in the number of setae.

Pereopod 5 (Fig. 3) Basis length 3.9 width, medially with two broom setae. Ischium length 2.37 width, dorsally with row of five slender setae. Merus length 1.3 width, with two small setae. Carpus length 3.17 width, with ventral row of 13 long slender setae and dorsal row of 11 setae, distodorsally one small broom seta. Propodus length 2.75 width, with ventral row of nine long setae and dorsal row of 10 setae, additionally with two simple setae. Dactylus length 5.25 times width, mediodistally with two small slender setae. Claw of dactylus with one long conate seta, two adjacent slender setae.

Pereopod 6 and 7 are similar to pereopod 5, differing only in the number of setae.

Pleopod 2 (operculum) (Fig. 4) length 1.2 width. Lateral margins straight, distal margin straight, with 30 simple setae.

Pleopod 3 (Fig. 4) Endopod length 1.31 width, distally with 3 long plumose setae. Exopod length 0.73 endopod length, margins hirsute, with one small distal seta.

Pleopod 4 (Fig. 4) Endopod oval-shaped, length 1.97 width. Exopod length 12 times width, distally with one long plumose seta.

Pleopod 5 (Fig. 4) Endopod only, length 3.08 width.

Uropods (Fig. 4) biramous. Endopod length 1.4 protopod length, 7.9 times longer than wide, marginally with one slender and two broom setae, distally with three small, one slender and six broom setae. Exopod length 5 times width, 0.3 endopod length, terminally with two setae. Protopod length 4.6 width, with few small slender setae.

Male:

Habitus (Fig. 5) similar to female, but Prn 1-4 as high as Prn 5-7, Plt with larger posterolateral spines.

Pleopod 1 (Fig. 5) 4.72 times longer than distal width, tips with distal bulges bearing four slender setae.

Pleopod 2 (Fig. 5) Sympod oval-shaped, length 1.37 width, lateral margin rounded, with seven slender setae. Endopod inserting at 0.49 of sympod's length.

Discussion: Prochelator tupuhi sp. nov. is assigned to the genus Prochelator on the basis of the carpochelate pereopod 1 (Wägele 1989, Brenke et al. 2005), one stout distally setulate seta midway on the ventral margin of the carpus, and the slender penultimate seta next to the large claw-seta.

Prochelator tupuhi is easy to distinguish from $P$. incomitatus and $P$. angolensis by having biramous uropods. Both of the latter species possess a very compact anterior part of the body, with pereonite 1 being twice as long as pereonite 2. Characters distinguishing P. tupuhi from other species of the genus with biramous uropods are: relatively elongate body without spine-like ventral elongations on pereonites 1-4 (as in P. lateralis, $P$. uncatus and P. hampsoni). The remaining species of the genus are anteriorly compact, pereonites 1-4 are higher than pereonites 5-7 from lateral view. In P. tupuhi pereonite 1 is as high as pereonite 5, the medial lobe of the maxilla is much shorter than in the other species of the genus, reaching only half the length of the outer lobe. The carpus of pereopod 1 is distinctly produced at the base of the claw-seta, the propodus is broadest at the articulation to the carpus and tapers distally.

Etymology: The epithet is the Māori word tupuhi meaning thin (noun in apposition). 


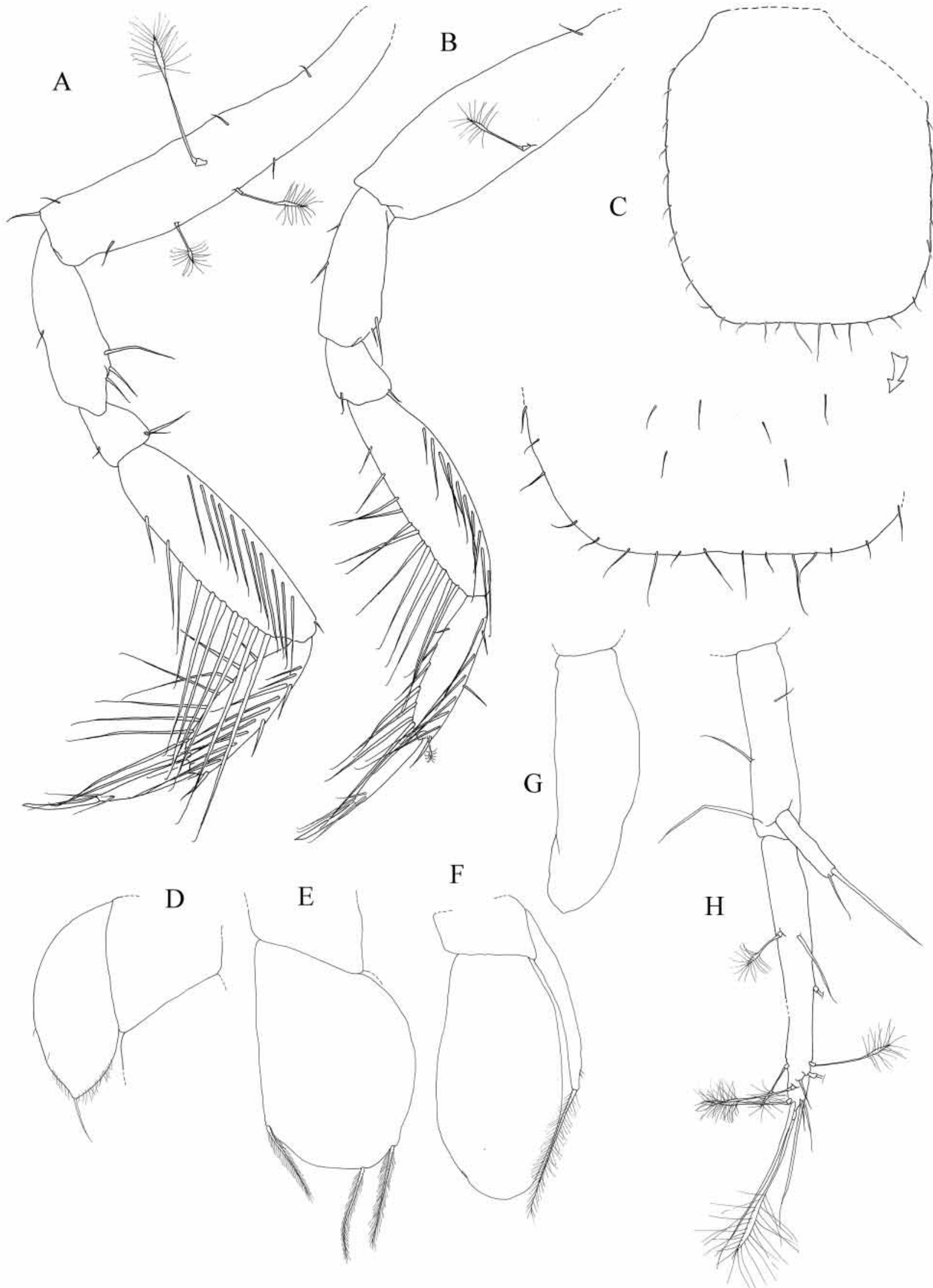

FIGURE 4: Prochelator tupuhi sp. nov., paratype female, pereopods (A-B): P 6 (A), P 7 (B), pleopods (C-H): operculum (C), exopod of Pl 3 (D), endopod of Pl 3 (E), Pl 4 (F), Pl 5 (G), uropod (H). 
A

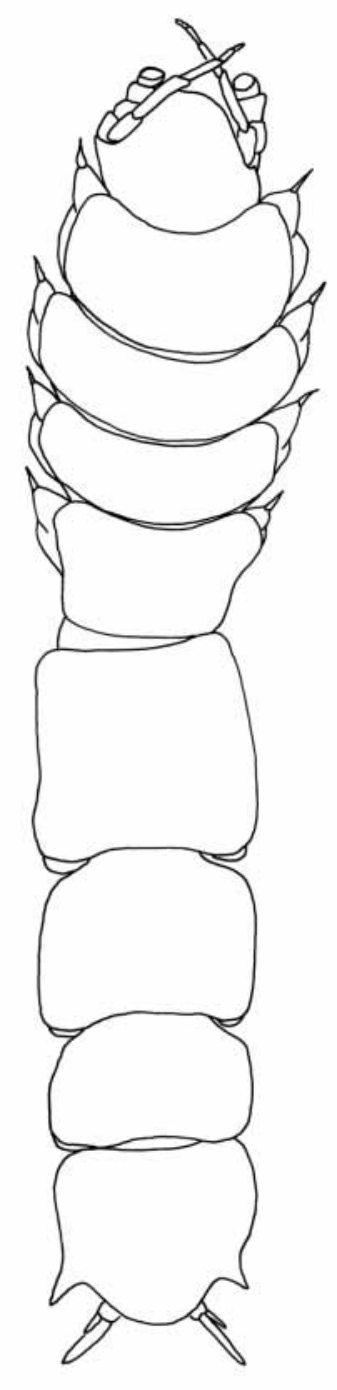

B

\section{(1)}

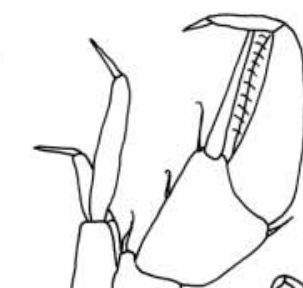

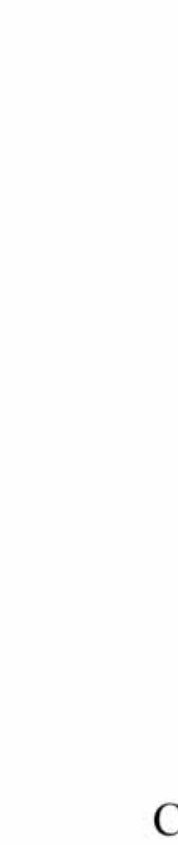
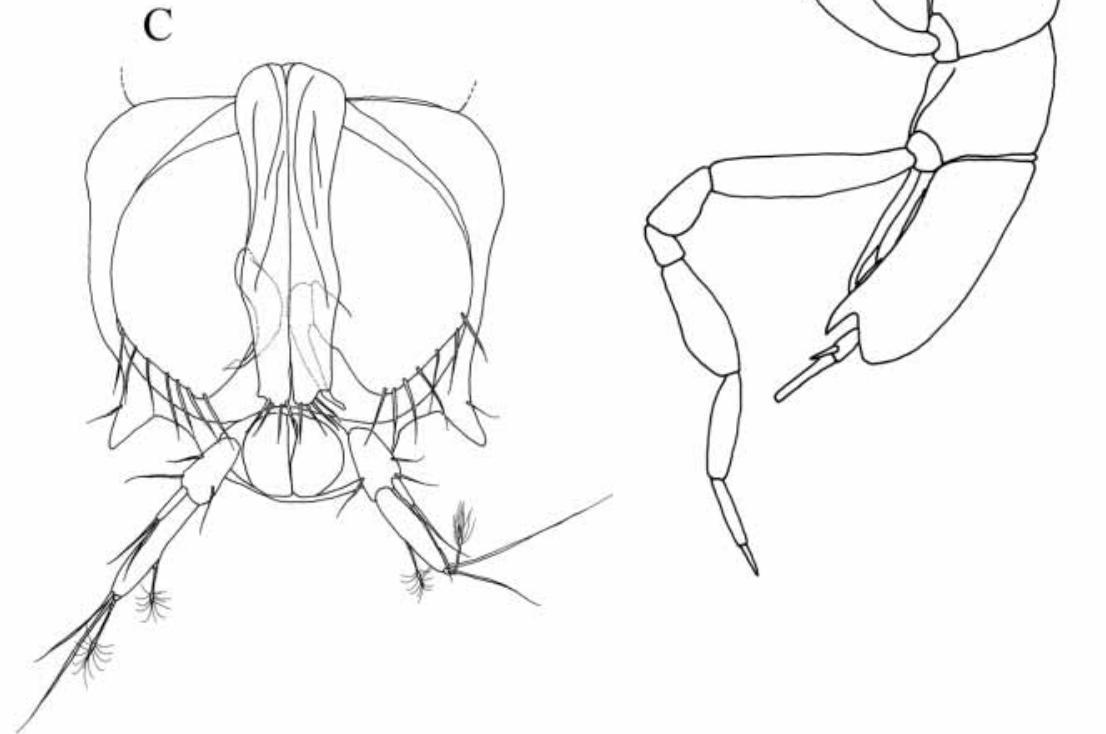

FIGURE 5: Prochelator tupuhi sp. nov., allotype male, habitus dorsal (A), lateral (B), pleotelson ventral (C).

\section{Acknowledgements}

Saskia Brix would like to thank Dr. Angelika Brandt for introducing her into deep-sea isopods and for organizing the financial support for working with the NIWA collection material. The staff of NIWA is thanked for their hospitality, with special thanks to Kelly Merrin and Dr. Anne-Nina Lörz. We thank Erica Williams (NIWA) for assistance with the Maori etymology. Financial support for Saskia Brix was provided by a grant of the German Science Foundation (DFG) under contract No Br 1121/22-1,2,3; Niel Bruce was supported by 
Foundation for Research, Science and Technology (FRST) program Biodiversity of New Zealand Aquatic Environments, C01X0502.

\section{References}

Brandt, A. (1993) Composition, abundance and diversity of peracarid crustaceans on a transect of the Kolbeinsey-Ridge, north of Iceland. Polar Biology, 13, 565-576.

Brandt, A., Brenke, N., Andres, H.-G., Brix, S., Guerrero-Kommritz, J., Mühlenhardt-Siegel, U. \& Wägele, J.-W. (2005) Diversity of Peracarid Crustaceans (Malacostraca) from the Abyssal Plain of the Angola Basin. Organisms Diversity \& Evolution, 5, 105-112.

Brandt, A., Brökeland, W., Brix, S. \& Malyutina, M. (2004) Diversity of Southern Ocean deep-sea Isopoda (Crustacea, Malacostraca) - a comparison with shelf data. Deep-Sea Research II, 51, 1753-1768.

Brandt, A., Brix, S., Brökeland, W., Cedhagen, T., Choudury, M., Cornelius, N., Danis, B., De Mesel, I., Diaz, R.J., Gillan, D.C., Hilbig, B., Howe, J., Janussen, D., Kaiser, S., Linse, K., Malyutina, M., Brandao, S., Pawlowski, J., Raupach, M., Gooday, A.J. (2007a) The Southern Ocean deep sea: first insights into biodiversity and biogeography. Nature, pp. 307-311.

Brandt, A., Brökeland, W., Brix, S. Choudhury, M., Kaiser, S. \& Malyutina, M. (2007b) Deep-sea isopod biodiversity, zoogeography and endemism in the Atlantic sector of the Southern Ocean - results from the ANDEEP I-III expeditions. Deep-Sea Research II 54 pp. 1760-1775.

Brenke, N. (2005) An epibenthic sledge for operations on marine soft bottom and bedrock. Marine Technology Society Journal, 39(2), 10-19.

Brenke, N., Brix, S. \& Knuschke, T. (2005) A new deep-sea isopod species from the Angola Basin: Prochelator angolensis sp. nov. (Asellota: Desmosomatidae). Organisms Diversity \& Evolution, 5, 179-188.

Brix, S. (2006) A new species of Desmosomatidae (Isopoda: Crustacea) from the deep Southern Ocean: Eugerdella serrata sp. nov. including remarks to the morphological variability within Eugerdella Hessler, 1970. Mitteilungen aus dem hamburger zoologischen Museum und Institut, 69-84.

Brix, S. (2007) Four new species of Desmosomatidae Sars, 1897 (Crustacea: Isopoda) from the deep sea of the Angola Basin. Marine Biology Research, 3:4, 205-230.

Fresi, E. \& Schiecke, U. (1969) Two new desmosomatids from the Gulf of Naples: Desmosoma serratum n. sp. and Desmosoma thoracicum n. sp. (Isopoda, Parasellidae). Crustaceana, 17 Part 2, 159-170.

George, R.Y. (2001) Desmosomatidae and Nannoniscidae (Crustacea, Isopoda, Asellota) from bathyal and abyssal depth off north Carolina and their evolution. Journal of Natural History, 35 No.12, 1831-1859.

Hessler, R.R. (1970) The Desmosomatidae (Isopoda, Asellota) of the Gay Head-Bermuda Transect. Bulletin of the Scripps Institution of Oceanography, 15, 1-185.

Kussakin, O.G. (1965) On the fauna of Desmosomatidae (Crustacea, Isopoda) on the Far-Eastern Seas of the U.S.S.R. Akademija Nauk SSSR, Zoologičeskij Institut Exploration of the fauna of the seas III (XI) Fauna Seas NW Pacific, 339-375.

Kussakin, O.G. (1999) Marine and salt-water Asellota (Isopoda) of the cold and temperate Waters of the northern hemisphere (in Russian). Vol. III. Suborder Asellota. Part 2. Nauka, Leningrad - AH SSSR, 383 pp.

Lincoln, R.J. (1985) The Marine Fauna of New Zealand: Deep-Sea Isopoda Asellota, family Haploniscidae. New Zealand Oceanographic Institute Memoirs, 94, 5-7.

Meinert, F. (1890) Crustacea Malacostraca. 232 pp.

Mezhov, B.V. (1986) Bathyal and abyssal Nannoniscidae and Desmosomatidae (Isopoda, Asellota) from Alaska Bay. Archives of Zoological Museum Moscow State University, 24, 126-167.

Poore, G.C.B., Just, J. \& Cohen, B.F. (1994) Composition and Diversity of Crustacea (Isopoda) of the Southern Australian Continental Slope. Deep Sea Research I, 41, 677-693.

Sars, G.O. (1864) On en anormal Gruppe af Isopoder. Forhandlinger I Videnskabs-Selskabet i Christiana, 1863, 1-16.

Sars, G. O. (1897) An account of the Crustacea of Norway. Volume 2, parts 3-8. Isopoda. Bergen. 103 pp.

Sars, G. O. (1899) An account of the Crustacea of Norway. Volume 2, parts 13-14. Isopoda. Bergen 270 pp.

Svavarsson, J. (1993) The deep-sea asellote (Isopoda, Crustacea) fauna of the Northern Seas: species composition, distributional patterns and origin. Journal of Biogeography, 537-555.

Wägele, J.-W. (1989) Evolution und phylogenetisches System der Isopoda. Stand der Forschung und neue Erkenntnisse. Zoologica, 140, 1-262.

Watling, L. (1989) A classification system for crustacean setae based on the homology concept. In: Felgenhauer, B.W., L.; Thistle, A.B. (Ed.) Functional morphology of feeding and grooming in Crustacea. A. A. Balkema, Rotterdam, pp. 15-26. 